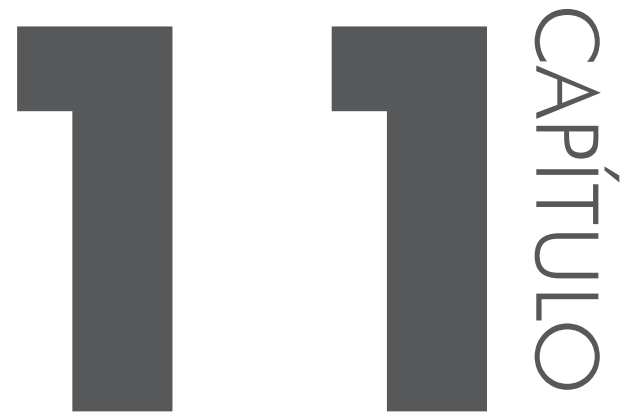

\title{
ETNOBOTÂNICA DE KIELMEYERA CORIACEA MART E ZUCC
}

Núbia Alves Mariano Teixeira Pires Gomides ${ }^{1}$ Antônia Caixeta Neta ${ }^{2}$ Richele Priscila Severino ${ }^{2}$ Vanessa Gisele Pasqualotto Severino ${ }^{2}$ Germano Guarim Neto ${ }^{1}$

Agradecimentos: À Universidade Federal de Goiás e à Universidade Federal do Mato Grosso; aos moradores do município de Goiandira que partilharam seus conhecimentos para contribuir com este estudo; e aos órgãos de fomento CNPq, FAPEG, FAPEMAT e CAPES.

1 Unidade de Biociências, Universidade Federal de Mato Grosso, Cuiabá, Brasil.

2 Unidade Acadêmica Especial de Física e Química, Universidade Federal de Goiás - Regional Catalão, Catalão, Brasil.

E-mail de contato: nubiamarianobio@gmail.com 
Resumo: Neste estudo, foi realizado o levantamento etnobotânico da espécie medicinal Kielmeyera coriacea Mart e Zucc por meio de entrevistas com moradores do município de Goiandira-GO. A técnica de seleção dos entrevistados foi a bola de neve. A espécie vegetal também foi investigada quimicamente através das técnicas de Prospecção Preliminar e Cromatografia em Camada Delgada para detecção de classes de produtos naturais presentes. Ressalta-se a importância do estudo para resgatar e registrar os saberes botânicos da comunidade de Goiandira, bem como subsidiar futuros estudos de prospecção de plantas bioativas. Em termos de citações para uso medicinal, as categorias que mais se destacaram, com os maiores valores do Índice de Diversidade de Uso, foram leucemia, anemia e gastrite. A infusão, chá, extração da entrecasca com leite, bem como sua mastigação são as formas mais utilizadas da planta. Várias indicações populares corroboraram com estudos que avaliam a atividade biológica de K. coriacea, sendo, portanto, importante a continuidade dos estudos para que todas as categorias indicadas sejam avaliadas biologicamente. Desse modo, K. coriacea é uma espécie promissora para a prospecção químico-biológica.

Palavras-chave: Cerrado. Kielmeyera coriácea. Produtos Naturais. Potencialidades.

Abstract: This study was carried out ethnobotanical survey of medicinal plant Kielmeyera coriacea Mart and Zucc, through interviews with residents of the municipality of Goiandira-GO. The selection of respondents technique was the snowball. The plant species was also investigated chemically by preliminary prospecting technique and thin layer chromatography to detect natural products present classes. It emphasizes the importance of studying to rescue and record the botanical knowledge of Goiandira community and facilitate future studies of prospecting bioactive plants. In terms of citations for medical use, categories that stood out with the highest values of the Use of Diversity Index were leukemia, anemia and gastritis. The infusion tea extraction of bark with milk, as well as their chewing are the most used forms of the plant. Several popular indications corroborate studies evaluating the biological activity of $K$. coriacea, it is therefore important for further study, so that all specified categories are evaluated biologically. Thus, K. coriacea is a promising species for the chemical-biological prospecting.

Keywords: Cerrado. Kielmeyera coriacea. Natural products. Potentialities.

\section{INTRODUC̣ÃO}

O conhecimento popular sobre o uso de plantas medicinais para o tratamento de enfermidades é um processo histórico que se alicerça nas culturas específi- 
cas de cada região, sendo a base para a comercialização, pois é a partir dele que são feitas as receitas caseiras. Em muitas comunidades e até mesmo nas grandes cidades é comum a comercialização de plantas medicinais em feiras e mercados populares. Desta forma, os constituintes químicos, as atividades biológicas e a toxicidade das plantas medicinais nem sempre são bem conhecidas e este fato acarreta grande interesse de pesquisadores de áreas multidisciplinares, como a botânica, a farmacologia e a fitoquímica para a investigação da flora medicinal (MACIEL et al., 2002).

O Cerrado, domínio bastante rico em flora, possui diversas espécies farmacologicamente ativas que são utilizadas na medicina popular em virtude da grande diversidade de ordens, famílias e gêneros. Segundo Pereira e Cardoso (2012), quanto maior a diversidade taxonômica em níveis superiores, maiores são o distanciamento filogenético entre as espécies, a diferença e a diversidade química entre elas, contribuindo para o grande potencial de compostos bioativos. Este domínio ocupa cerca de 2 milhões de $\mathrm{km}^{2}$, ou $22 \%$ do território brasileiro, e se situa no coração da América do Sul. Em extensão, o Cerrado fica atrás apenas da Amazônia e ocorre nos estados de São Paulo, Minas Gerais, Goiás, Mato Grosso, Mato Grosso do Sul, Tocantins, Bahia, Maranhão, Piauí e Distrito Federal. Além disso, incorpora ainda partes do território de países vizinhos como Bolívia e Paraguai. Abriga diversidade biológica comparável às florestas úmidas, como a Amazônica e a Atlântica, tem sofrido intensa degradação de seus hábitats e é, portanto, considerado um dos 35 hotspots de biodiversidade do mundo (MITTERMEIER et al., 1999). No Cerrado há mais de 12.000 espécies conhecidas da sua flora, das quais 44\% endêmicas. No entanto, 645 espécies encontram-se ameaçadas de extinção, o que representa mais de $30 \%$ presentes na lista vermelha do Brasil (SCARANO et al., 2014).

Uma característica essencial do Cerrado é a sua geografia, a qual proporciona contato com as fitosionomias vizinhas, Mata Atlântica, Amazônia e Caatinga. Os grandes tributários da margem direita do Amazonas, como Tapajós, Xingu e Tocantins, nascem e percorrem boa parte do seu curso no Cerrado, e suas matas ribeirinhas atuam como corredores de conexão entre a planície amazônica e o planalto. Da mesma forma, as nascentes dos rios das bacias do Paraná e Paraguai se estendem até a área central dos Cerrados, permitindo a dispersão de espécies de Mata Atlântica ao longo desses cursos. O Cerrado contribui com a vazão que flui em oito das doze regiões hidrográficas brasileiras definidas pela Agência Nacional das Águas, reafirmando a relevância deste domínio para a manutenção dos recursos hídricos do país (SCARANO et al., 2014).

As ameaças registradas nas avaliações de risco de extinção das plantas raras do Cerrado refletem a evolução da sua ocupação histórica. A incidência das ame- 
aças envolve, de maneira geral, a atividade mineradora e posterior expansão da fronteira agrícola, além de outras ameaças relacionadas a essas atividades, como os incêndios antrópicos, utilizados principalmente para o manejo do solo, e a consequente invasão de espécies exóticas. Portanto, a área vegetal do Cerrado é impactada e ainda não há medidas legais que inibam a devastação acelerada. Sendo assim, várias espécies vegetais de uso popular estão se extinguindo antes de serem estudadas pela comunidade científica, as quais apresentam possibilidade de serem promissoras para os estudos de bioprospecção (MARTINELLI et al., 2014).

Neste contexto, a família Calophyllaceae é uma importante representante das espécies vegetais do Cerrado, apresentando espécies endêmicas e raras. Antiga subfamília Kielmeyeroideae de Clusiaceae, apresenta distribuição pantropical e é representada por 14 gêneros e 460 espécies.No Brasil são listados oito gêneros (Calophyllum, Caraipa, Clusiella, Haploclathra, Kielmeyera, Mahurea, Mammea e Marila) e cerca de 80 espécies, das quais mais da metade são endêmicas e muitas podem ser apontadas como raras ou em risco de extinção (JORGE, 2014).

O gênero Kielmeyera merece destaque na flora brasileira, pois contém cerca de 50 espécies, sendo a maioria do Cerrado. Algumas são frequentes e bem distribuídas, como K. coriacea Mart. \& Zucc. eK. rubriflora Cambess, enquanto a grande maioria apresenta uma distribuição mais restrita. Há ainda um número considerável de espécies raras para este domínio fitogeográfico, sendo quatro delas descritas no Livro Vermelho da Flora do Cerrado: K. anisosepala Saddi, K. juruenensis Saddi, K. similis Saddi e K. trichophora Saddi (JORGE, 2014).

K. coriacea Mart e Zucc., conhecida como pau-santo, tem sua distribuição abrangendo os estados da Bahia, Goiás, Maranhão, Mato Grosso, Mato Grosso do Sul, Minas Gerais, Paraná, Piauí, São Paulo, Tocantins e Distrito Federal (LORENZI, 1992). De acordo com Almeida (1946), é uma espécie caducifólia, pode atingir uma altura de 6 metros, suas folhas são simples e ficam concentradas no ápice dos ramos. A floração ocorre de outubro a dezembro e a frutificação entre novembro e setembro. Os frutos são carnosos, alongados e ásperos. Lorenzi (1992) complementa que a dissipação das sementes ocorre principalmente pelo vento.

Guarim Neto e Morais (2003) destacam em levantamento bibliográfico realizado, doze autores que citam a presente espécie com utilização medicinal, em diferentes comunidades. Desta forma, é comumente indicada para o uso medicinal geral (LIMA et.al., 2012), como emoliente (RODRIGUES; CARVALHO, 2001), vermífugo (SOUZA; FELIFILI, 2006), dermatoses e depurativos (FERREIRA et al., 2013), esquitossomose, leishamiose, malária, infecções fúngicas e bacterianas (ALVES et al., 2000). 
Em virtude do uso contínuo de K. coriacea em comunidades, sendo uma espécie nativa do Cerrado, torna-se necessário realizar o registro dos conhecimentos etnobotânicos, incluindo as formas de uso e para quais enfermidades é empregada. Tais indicações servem como subsídios para novos estudos relacionados ao conhecimento da composição química e atividades biológicas da espécie, agregando valor intrínseco pelas suas propriedades medicinais, além de incentivar planos de conservação e manejo da biodiversidade do Cerrado.

Neste contexto, o presente trabalho objetivou realizar um levantamento etnobotânico de K. coriácea com o intuito de registrar informações sobre os usos desta espécie por moradores do município de Goiandira, Goiás, e identificar as classes de produtos naturais (PNs) presentes, bem como as atividades biológicas registradas na literatura, relacionando-as à investigação em questão.

\section{METODOLOGIA}

\section{1 Área do estudo}

O estudo foi realizado no município de Goiandira, local em que o saber etnobotânico está arraigado na cultura e costumes populares, ainda que tenha havido uma perda de conhecimentos entre as gerações. Assim, faz-se necessário compreender a história do município, a qual é contextualizada a seguir, e buscar o etnoconhecimento nas gerações mais antigas.

Há indicações que havia índios nesta região, pois foram encontrados utensílios de barro com caracteres de cerâmica indígena nas escavações feitas bem perto das margens dos ribeirões Fartura e Dourados, atual fazenda Água Fria. Além disso, há um casal de procedência aborígene, família de bugres, que deixou como descendente a filha, que reside no Asilo Municipal. Provavelmente, os índios que habitaram Goiandira até meados do século XVIII foram os Caiapós, que residiram nas proximidades dos Rios Veríssimo, Corumbá, Piracanjuba, dos Bois, Turvo, Claro, Pardo e Paranaíba (ARAÚJO, 2000; IBGE, 2010). Há relatos de que os índios no Brasil utilizavam K. coriacea em preparações que possuem ação no sistema nervoso central (RODRIGUES; CARLINI, 2005); ademais, da entrecasca é extraída uma resina amarela tônica e emoliente utilizada no tratamento de dores de dentes (CORREA,1969). Tais conhecimentos podem ter sido transmitidos para as gerações presentes.

Além dos índios residentes na região, as bandeiras começaram a chegar à região, denominada Sesmaria de Campo Limpo; este foi o primeiro passo para a ocupação colonial do território. A Sesmaria de Campo Limpo era habitada, em sua maioria, pelas famílias Garcia e Teixeira que moravam nas fazendas, sendo a sede acompanhada por conjuntos de ranchos. 
Tomás Garcia e Jerônimo Teixeira foram os pioneiros da Sesmaria em 1800. Em seguida, outras famílias vieram para a região à procura de terras melhores, (ARAÚJO, 2000).

A ocupação desta região foi influenciada pela presença da estrada de ferro e a fazenda Campo Limpo sediou a estação ferroviária denominada de Goiandira, criada em 1911. No ano seguinte, já havia diversas residências e comércios, provocando a urbanização da região, que se tornou distrito em 25 de janeiro de 1915, pela Lei Municipal n ${ }^{\circ}$ 39, editada pela Prefeitura de Catalão-GO. Em 1923, o distrito passou a ter abastecimento de energia elétrica, estimulando ainda mais o desenvolvimento ocorrido em decorrência da estrada de ferro (ARAÚJO, 2000).

A emancipação política de Goiandira foi concedida em 6 de maio de 1931, por meio do Decreto $n^{\circ} 799$; em 28 de maio este território foi acrescido do Distrito de Nova Aurora, que até então pertencia à Corumbaíba, por meio do Decreto $\mathrm{n}^{\circ}$ 1.112. O município de Goiandira era composto pelos distritos de Cumari e Nova Aurora, que tiveram sua emancipação, respectivamente, em 10 de dezembro de 1947 e 11 de novembro de 1953. Atualmente, o município de Goiandira é formado por um único Distrito e pelo Povoado de Veríssimo (ARAÚJO, 2000).A proposta de conhecer um pouco da história do município advém do anseio de no presente e num futuro próximo ainda haver recursos naturais fazendo parte da história da cidade, sendo respeitados e vistos como importantes. É preciso que o homem se veja inserido na natureza como um dos membros dela, não como proprietário, e que possa valorizar as terras que possui de forma a garantir a existência das outras espécies.

O município de Goiandira (Figura 1) tem como domínio vegetacional o Cerrado, que ocorre na parte central do país. Localiza-se ao Centro-Sul do Estado de Goiás, latitude $18^{\circ} 07^{\prime} 54^{\prime}$ 'S, longitude $48^{\circ} 05^{\prime} 06^{\prime \prime W}$, a uma altitude de 848 metros, distando $280 \mathrm{~km}$ da capital, Goiânia. A região é de fácil acesso pela GO-210. O município possui uma área de $562,5 \mathrm{~km}^{2}$ e uma população de 4.925 habitantes, com densidade de 8,3 habitantes $/ \mathrm{km}^{2}$, sendo que a área urbanizada é de 0,368 $\mathrm{km}^{2}$, e a área rural é de $562,13 \mathrm{~km}^{2}$ (IBGE, 2012).

De acordo com o IBGE (2012), este município possui a agricultura desenvolvida nos produtos arroz, banana, café, cana-de-açúcar, feijão, mandioca, milho, palmito e soja. Por possuir a maior parte de suas terras para a agropecuária, a cidade tem o perfil agropecuário. A população residente na área urbana ainda mantém laços com a área rural, o que possibilita a existência do conhecimento botânico e medicinal na comunidade; a etnobotânica, portanto, registra tais conhecimentos. 


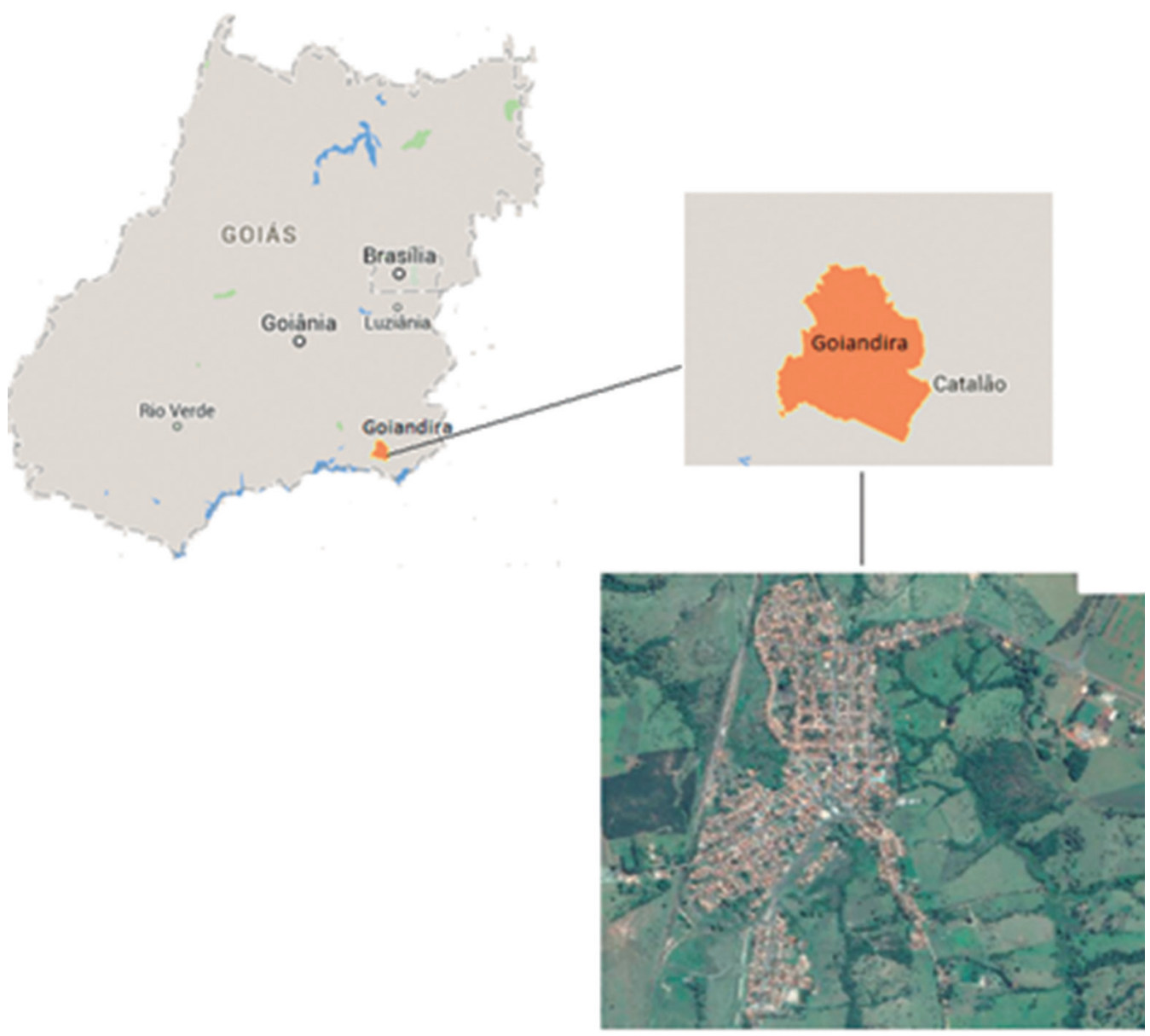

Figura 1. Localização do município de Goiandira-G0. Fonte: adaptada de IBGE (2012).

\subsection{Métodos etnobotânicos}

Para a pesquisa etnobotânica, a amostragem não deve ser ao acaso ou aleatória, mas sim dirigida aos elementos da população que à partida poderão saber mais acerca da temática que se pretende abordar (CAMEJO RODRIGUES, 2007). Para localizar pessoas com essas características, recorre-se à técnica bola de neve (snowball), que consiste no primeiro entrevistado indicar o próximo e assim por diante (THIOLLENT, 1994; BECKER, 1993).

Quanto aos métodos de escolha de dados, há dois muito citados e usados na etnobotânica - a entrevista etnobotânica e a observação/participação. Neste estudo foi desenvolvida a técnica de entrevista estruturada, que é "como se fosse um 
questionário, mas utilizado de modo mental pelo entrevistador (e não preenchido pelo entrevistado)" (RODRIGUES, 2007).

Para a realização das entrevistas de forma legal, o projeto foi submetido ao Comitê de Ética da Universidade Federal de Goiás, aprovado em 02/04/2012, sob o número de protocolo 033/12. Como requisito básico para realização das entrevistas foi solicitada a assinatura do termo de consentimento livre e esclarecido a cada informante.

As entrevistas foram direcionadas para obter dos informantes a socialização de seus conhecimentos sobre K. coriacea. Neste aspecto, foram entrevistadas 25 pessoas individualmente, priorizando atores sociais como raizeiros, benzedeiras, antigas parteiras, pessoas idosas e antigos moradores. As visitas em domicílios ocorreram no mês de abril de 2013, em quatro finais de semana, nos períodos matutino e vespertino.

A coleta de dados na entrevista compreendeu: (a) nome do entrevistado; (b) idade do entrevistado; (c) conhecimento da espécie; (d) usos medicinais da espécie; (e) parte da planta utilizada no preparo medicinal; e (f) formas de preparo medicinal.

O conhecimento local foi analisado através de medidas quantitativas, as quais têm como objetivo refletir a concordância entre os informantes sobre o conhecimento da espécie (FEITOSA, 2012) (Tabela1). Os dados foram tabulados no Microsoft Office Excel 2007.

Tabela 1. Medidas de uso e conhecimento calculados para K. coriacea

\begin{tabular}{cc}
\hline Índices & Cálculo \\
\hline $\begin{array}{c}\text { Valor da diversidade do } \\
\text { informante (VDI) }\end{array}$ & $\begin{array}{c}\text { VDI = número de usos citados por determinado } \\
\text { informante dividido pelo número de usos totais. } \\
\text { VCTU = número de vezes em que determinado uso } \\
\text { foi reportado dividido pelo número total de usos. } \\
\text { tipos de usos (VCTU) } \\
\text { O valor encontrado é dividido pela quantidade de } \\
\text { categorias de uso. }\end{array}$ \\
$\begin{array}{c}\text { Valor de diversidade de uso } \\
\text { (VDU) }\end{array}$ & $\begin{array}{c}\text { VDU = número de indicações registradas por } \\
\text { categorias de uso dividido pelo número total de } \\
\text { indicações de uso. }\end{array}$ \\
$\begin{array}{c}\text { Valor de consenso para a } \\
\text { forma de uso (VCFU) }\end{array}$ & $\begin{array}{c}\text { forma de uso dividido pelo total de citações para as } \\
\text { todas as formas. }\end{array}$ \\
$\begin{array}{c}\text { Valor de consenso para a a } \\
\text { parte da planta (VCPP) }\end{array}$ & $\begin{array}{c}\text { VCPP = número de vezes em que determinada parte } \\
\text { da planta foi citada dividido pelo número total de } \\
\text { citações de todas as partes. }\end{array}$ \\
\hline
\end{tabular}

Fonte: Feitosa (2012). 


\subsection{Métodos químicos}

A entrecasca foi selecionada para coleta como foco do estudo de Prospecção Preliminar para detecção de classes de PNs em virtude do alto número de indicação dessa parte vegetal nas entrevistas realizada na comunidade. Neste sentido, a identificação e catalogação de K. coriacea foram realizadas pela Me. Núbia Alves Mariano Teixeira Pires Gomides e os espécimes testemunhos foram depositados no Herbário da Embrapa Recursos Genéticos e Biotecnologia (CEN), sob o número BW 6046. O material foi coletado no dia 11 de abril de 2015 na comunidade de Goiandira-GO, com a autorização de acesso e de remessa de amostra de componente do patrimônio genético sob o número 010698/2013-2. Os dados e as coordenadas da coleta (GPS) foram armazenados para coletas futuras.

Após a coleta, a entrecasca fresca foi cortada em partes menores. Posteriormente, foram pesados 40 gramas deste material, o qual foi suspenso em 200 mililitros de etanol 92,8\%, gerando uma solução que foi levada a banho-maria a $60{ }^{\circ} \mathrm{C}$, agitando frequentemente por 10 minutos para dissolução total. Ainda quente, a solução foi filtrada em um pano fino e em papel filtro, originando-se o extrato vegetal (EV), o qual foi armazenado em tubo do tipo Falcon e conservado à baixa temperatura.

Para o desenvolvimento do processo de análise fitoquímica, utilizou-se as metodologias de Prospecção Preliminar (PP) e Cromatografia em Camada Delgada (CCD), ambas adaptadas da literatura (MATOS, 1997). As correlações das utilizações medicinais pela comunidade supracitada com informações científicas também foram abordadas neste estudo.

\subsubsection{Prospecção Preliminar (PP)}

Para a técnica de PP foram empregadas as seguintes soluções reveladoras: cloreto férrico $10 \%(\mathrm{~m} / \mathrm{v})$, hidróxido de sódio $1 \%(\mathrm{~m} / \mathrm{v})$, ácido clorídrico $1 \%(\mathrm{v} / \mathrm{v})$ e reagente Lieberman-Buchard. O preparo destas soluções se deu da seguinte forma:

- Cloreto férrico $10 \%(\mathrm{~m} / \mathrm{v})$ : uma alíquota de $10 \mathrm{~g}$ foi pesada e solubilizada em água destilada, transferindo-se a solução resultante para um balão de $100 \mathrm{~mL}$. Agitou-se para homogeneizar;

- Hidróxido de sódio $1 \%(\mathrm{~m} / \mathrm{v})$ : uma alíquota de $1 \mathrm{~g}$ foi pesada e solubilizada em água destilada, transferindo-se a solução resultante para um balão de $100 \mathrm{~mL}$. Agitou-se para homogeneizar;

- Ácido clorídrico $1 \%(\mathrm{v} / \mathrm{v})$ : transferiu-se $1 \mathrm{~mL}$ de ácido clorídrico concentrado para um balão de $100 \mathrm{~mL}$ e completou-se com água destilada até o menisco;

- Reagente Dragendorff: em banho de gelo, dissolveu-se $5 \mathrm{~g}$ de carbonato de bismuto em $50 \mathrm{~mL}$ de água, adicionando cuidadosamente $12 \mathrm{~mL}$ de 
ácido clorídrico concentrado. Posteriormente, acrescentou-se gradativamente 25 g de iodeto de potássio; após a dissolução completa, completou-se o volume para $100 \mathrm{~mL}$ com água destilada;

- Reagente Lieberman-Buchard: adicionou-se $5 \mathrm{~mL}$ de anidrido acético e $5 \mathrm{~mL}$ de ácido sulfúrico $98 \%$ a $50 \mathrm{~mL}$ de álcool etílico absoluto sob resfriamento.

Para detecção de algumas classes de PNs, empregou-se a metodologia descrita a seguir:

a) Esteroides/triterpenoides: os testes foram realizados pela reação de Lieberman-Burchard, tomando-se $2 \mathrm{~mL}$ de EV e misturando-o a $2 \mathrm{~mL}$ de clorofórmio. Em seguida, a solução clorofórmica foi filtrada, gota a gota, em um funil com algodão coberto com alguns decigramas de sulfato de sódio anidro. Em um tubo de ensaio, adicionou-se $1 \mathrm{~mL}$ de anidrido acético, agitando suavemente e acrescentou-se cuidadosamente três gotas de ácido sulfúrico concentrado, agitando suavemente e observando se haveria aparecimento de cor. A coloração azul evanescente seguida de verde indicou a presença de esteroides/triterpenóoides, respectivamente.

b) Flavonoides: o teste de cianidina ou Shinoda (ácido clorídrico concentrado e magnésio) foi realizado pela adição de $2 \mathrm{~mL}$ de EV, $0,5 \mathrm{~cm}$ de magnésio em fita e2,0 $\mathrm{mL}$ de ácido clorídrico concentrado. $\mathrm{O}$ término da reação se deu pelo cessar da efervescência. $O$ aparecimento da coloração que variou de parda a vermelha indicou a presença de flavonoides.

c) Taninos: em um tubo de ensaio contendo 2,0 $\mathrm{mL}$ de EV adicionou-se três gotas de solução alcoólica de cloreto férrico 10\%, agitando-se fortemente e observando-se qualquer variação de cor. O precipitado de tonalidade azul ou verde indicou a presença de taninos.

d) Saponinas: em um tubo de ensaio contendo $2 \mathrm{~mL}$ de EV foram adicionados $5 \mathrm{~mL}$ de água fervente. Após esfriar, agitou-se vigorosamente por 20 minutos. O tubo foi deixado em repouso por 10 minutos, logo após observou-se se a espuma continuava persistente ou não. Espuma persistente e abundante (colarinho) indicou a presença de saponina.

e) Alcaloides: em um tubo de ensaio alcalinizado com 15 gotas de hidróxido de sódio (1\%) e acrescido de $2 \mathrm{~mL}$ de água, adicionou-se $2 \mathrm{~mL}$ de EV e $2 \mathrm{~mL}$ de clorofórmio. A fração aquosa foi desprezada e à fração clorofórmica foram adicionadas 15 gotas de ácido clorídrico (1\%) e realizada a extração com $2 \mathrm{~mL}$ de água. A fração clorofórmica foi então desprezada e os testes foram realizados com a fração aquosa ácida, em que se acrescentou três gotas do reagente de Dragendorff para a verificação da presença de alcaloides. A formação de precipitados insolúveis e floculosos confirmou a presença de alcaloides. 


\subsubsection{Cromatografia em Camada Delgada (CCD)}

A entrecasca foi seca em estufa de circulação a $40{ }^{\circ} \mathrm{C}$ e pulverizadas em moinho até reduzirem-se a um pó fino; $10 \mathrm{~g}$ deste material foi submetido à extração com etanol $92,8 \%$ por três dias sem aquecimento. Após isso, a solução foi filtrada e o solvente evaporado à baixa pressão. Este processo se repetiu por trêsvezes, obtendo-se assim o EV.

Em seguida, uma alíquota do EV foi aplicada em uma placa cromatográfica, a qual foi inserida em uma cuba cromatográfica contendo a fase móvel (sistema de solventes descrito a seguir). Após eluição, a placa foi retirada da cuba, deixada em repouso até evaporação completa do solvente e levada à revelação na câmara do ultravioleta em comprimentos de onda de 254 e 365 nanômetros, sendo marcadas com um lápis as manchas observadas.

Sistema de solventes empregados:

1) Hexano/acetato de etila $(2: 8, \mathrm{v} / \mathrm{v})$;

2) Clorofórmio/metanol $(9: 1, \mathrm{v} / \mathrm{v})$;

3) Clorofórmio/metanol/água (6,5: 3,0: 0,5, v/v/v).

Posteriormente, a placa foi revelada com reveladores específicos para cada classe de PNs pesquisada, os quais são descritos a seguir:

a) Detecção de esteroides e triterpenoides: a placa foi imersa em uma solução de anidrido acético com ácido sulfúrico concentrado e aquecida por alguns minutos a $100{ }^{\circ} \mathrm{C}$. Os esteroides e triterpenoides foram identificados por manchas de coloração verde ou azul.

b) Detecção de flavonoides e terpenoides: a placa foi imersa em uma solução de sulfato cérico e aquecida por alguns minutos a $100{ }^{\circ} \mathrm{C}$. Os flavonoides e terpenoides foram identificados por manchas amarelas e roxas, respectivamente.

c) Detecção de taninos: a placa foi imersa em uma solução de cloreto férrico. Os taninos foram identificados por manchas de coloração azul escuro.

d) Detecção de alcaloides: a placa foi imersa em uma solução de Dragendorff. Os alcaloides foram identificados por manchas alaranjadas.

\section{RESULTADOS E DISCUSSÕES}

Auricchio e Bacchi (2003) e Sá (2008) evidenciam que apenas um pequeno percentual das espécies vegetais foi adequadamente estudado no que se refere às atividades farmacológicas. A seleção de plantas a serem investigadas, considerando a imensa quantidade que há a explorar, torna-se difícil. Nesse sentido, os relatos da medicina popular são eficazes para guiar a identificação de espécies vegetais potencialmente terapêuticas (PEREIRA; CARDOSO, 2012). 
Neste contexto, a espécie $K$. coriacea é muito indicada pela comunidade de Goiandira em diversas categorias de usos, sendo que algumas ainda não foram investigadas farmacologicamente, demonstrando, portanto, a relevância dessa planta. O levantamento etnobotânico realizado revelou que dos 25 informantes entrevistados, com faixa etária de 50 a 74 anos de idade, $76 \%$ conhecem e já utilizaram a espécie foco do estudo pelo menos uma vez, para tratar alguma enfermidade. Seis deles apenas conhecem a planta, mas relataram não saber de usos medicinais. Os dados de K. coriacea coletados nas entrevistas são expressos na Tabela 2.

Tabela 2. Levantamento etnobotânico no município de Goiandira

\begin{tabular}{|c|c|c|c|}
\hline $\begin{array}{l}\text { Idade e sexo do } \\
\text { entrevistado }\end{array}$ & Indicação de uso medicinal & $\begin{array}{l}\text { Parte da planta } \\
\text { utilizada }\end{array}$ & Forma de uso \\
\hline $64 /$ masculino & $\begin{array}{l}\text { Leucemia } \\
\text { Anemia }\end{array}$ & Entrecasca & $\begin{array}{c}\text { Extrair com leite; utilizar } \\
\text { pequenas porções } \\
\text { diariamente }\end{array}$ \\
\hline \multirow[t]{2}{*}{$74 /$ masculino } & $\begin{array}{c}\text { Gastrite } \\
\text { Dor de estômago }\end{array}$ & Galho fino & $\begin{array}{c}\text { Amassar e colocar de } \\
\text { molho na água por } 24 \\
\text { horas }\end{array}$ \\
\hline & $\begin{array}{l}\text { Anemia } \\
\text { Leucemia }\end{array}$ & $\begin{array}{l}\text { Entrecasca e } \\
\text { folhas }\end{array}$ & $\begin{array}{c}\text { Chá das partes em } \\
\text { conjunto }\end{array}$ \\
\hline 72/feminino & $\begin{array}{l}\text { Dor na gengiva } \\
\text { Dor de dente } \\
\text { Cárie }\end{array}$ & $\begin{array}{l}\text { Entrecasca } \\
\text { fresca }\end{array}$ & Mastigação \\
\hline \multirow[t]{3}{*}{$60 /$ masculino } & $\begin{array}{c}\text { Artrite } \\
\text { Artrose } \\
\text { Anemia } \\
\text { Leucemia } \\
\text { Infecções intestinais }\end{array}$ & $\begin{array}{l}\text { Entrecasca ou } \\
\text { folhas }\end{array}$ & $\begin{array}{l}\text { Amassar e deixar de } \\
\text { molho; posteriormente } \\
\text { tomar. }\end{array}$ \\
\hline & Cicatrização & & Fazer o emplasto \\
\hline & Gastrite & Entrecasca & $\begin{array}{l}\text { Extrair com leite; utilizar } \\
\text { pequenas porções } \\
\text { diariamente }\end{array}$ \\
\hline $55 /$ masculino & $\begin{array}{l}\text { Gastrite } \\
\text { Anemia } \\
\text { Leucemia } \\
\text { Vermífugo }\end{array}$ & Entrecasca & $\begin{array}{c}\text { Amassar e fazer a infusão } \\
\text { com água }\end{array}$ \\
\hline
\end{tabular}




\begin{tabular}{|c|c|c|c|}
\hline $\begin{array}{l}\text { Idade e sexo do } \\
\text { entrevistado }\end{array}$ & Indicação de uso medicinal & $\begin{array}{l}\text { Parte da planta } \\
\text { utilizada }\end{array}$ & Forma de uso \\
\hline \multirow{8}{*}{$66 /$ masculino } & Artrite & & \\
\hline & Artrose & & \\
\hline & Leucemia & Entrecasca ou & Infusão \\
\hline & Anemia & & \\
\hline & Vermífugo & & \\
\hline & Cicatrização & Entrecasca & $\begin{array}{l}\text { Fazer um melado e } \\
\text { utilizar como emplasto }\end{array}$ \\
\hline & Dor de dente & & Mastigação \\
\hline & Gastrite & Galho fino & Moer e fazer um melado \\
\hline $50 /$ masculino & Dor nos rins & Entrecasca & Chá \\
\hline 70/masculino & $\begin{array}{l}\text { Todos os tipos de } \\
\text { infecções }\end{array}$ & Entrecasca & Infusão \\
\hline 53/masculino & $\begin{array}{c}\text { Reumatismo } \\
\text { Gastrite }\end{array}$ & $\begin{array}{l}\text { Entrecasca ou } \\
\text { folhas }\end{array}$ & Chá \\
\hline $71 /$ masculino & $\begin{array}{l}\text { Anemia } \\
\text { Leucemia }\end{array}$ & Entrecasca & $\begin{array}{c}\text { Amassar e deixar de } \\
\text { molho; posteriormente } \\
\text { tomar }\end{array}$ \\
\hline $63 /$ feminino & Leucemia & Entrecasca & $\begin{array}{c}\text { Amassar e deixar de } \\
\text { molho; posteriormente } \\
\text { tomar }\end{array}$ \\
\hline 54/masculino & $\begin{array}{l}\text { Dor nos rins } \\
\text { Vermífugo }\end{array}$ & Entrecasca & Infusão \\
\hline 63/masculino & Reumatismo & $\begin{array}{l}\text { Entrecasca ou } \\
\text { folhas }\end{array}$ & Chá \\
\hline $55 /$ masculino & $\begin{array}{c}\text { Dor de dente } \\
\text { Cárie }\end{array}$ & Entrecasca & Mastigação \\
\hline $57 /$ masculino & Vermífugo & Entrecasca & $\begin{array}{c}\text { Extrair com leite; utilizar } \\
\text { pequenas porções } \\
\text { diariamente }\end{array}$ \\
\hline $59 /$ masculino & $\begin{array}{c}\text { Infecções de útero } \\
\text { Infecções de intestino } \\
\text { Dor nos rins } \\
\text { Reumatismo }\end{array}$ & Entrecasca & Infusão \\
\hline
\end{tabular}




\begin{tabular}{cccc}
\hline $\begin{array}{c}\text { Idade e sexo do } \\
\text { entrevistado }\end{array}$ & Indicação de uso medicinal & $\begin{array}{c}\text { Parte da planta } \\
\text { utilizada }\end{array}$ & Forma de uso \\
\hline $66 /$ masculino & Cicatrização & Entrecasca & $\begin{array}{r}\text { Fazer um melado e } \\
\text { utilizar como emplasto }\end{array}$ \\
$51 /$ masculino & $\begin{array}{c}\text { Aeucemia } \\
\text { Gastrite }\end{array}$ & Entrecasca & Infusão \\
\hline
\end{tabular}

Em relação ao conhecimento dos informantes, foi observado que alguns demonstram saber mais do que outros sobre os diversos usos da espécie, uma vez que indicaram mais categorias. Isso também pode ser constatado através do Valor da Diversidade do Informante (VDI) (Tabela 3), que expressa como os informantes usam a espécie e como esse uso encontra-se distribuído no município.

Tabela 3. Cálculo do Valor de diversidade do informante (VDI)

\begin{tabular}{cc}
\hline Idade do informante & VDI \\
\hline 66 & 0,16 \\
60 & 0,14 \\
74 & 0,08 \\
55 & 0,08 \\
59 & 0,08 \\
72 & 0,06 \\
51 & 0,06 \\
64 & 0,04 \\
53 & 0,04 \\
71 & 0,04 \\
54 & 0,04 \\
55 & 0,04 \\
50 & 0,02 \\
70 & 0,02 \\
63 & 0,02 \\
63 & 0,02 \\
57 & 0,02 \\
66 & 0,02 \\
53 & 0,02 \\
\hline
\end{tabular}


As informações obtidas sobre os distintos usos de K. coriacea, conhecida popularmente como pau-santo, atribuíram 16 indicações terapêuticas (categorias) (Tabela 4). O índice de Valor de Diversidade de Uso (VDU) retrata a importância e a contribuição das categorias de uso em relação ao valor total de usos. As categorias que mais se destacaram foram: leucemia, anemia e gastrite.

Tabela 4. Cálculo do Valor de Diversidade do Uso (VDU)

\begin{tabular}{cc}
\hline Indicação de uso medicinal & VDU \\
\hline Leucemia & 0,16 \\
Anemia & 0,14 \\
Gastrite & 0,12 \\
Dor de estômago & 0,02 \\
Dor na gengiva & 0,02 \\
Dor de dente & 0,06 \\
Cárie & 0,04 \\
Artrite & 0,04 \\
Artrose & 0,04 \\
Infecções intestinais & 0,04 \\
Cicatrização & 0,06 \\
Vermífugo & 0,1 \\
Dor nos rins & 0,06 \\
Todos os tipos de infecções & 0,02 \\
Reumatismo & 0,06 \\
Infecções de útero & 0,02 \\
\hline
\end{tabular}

O Valor de Consenso para os Tipos de Usos (VCTU) infere o grau de concordância entre os informantes e os usos indicados para K. coriacea. Sendo assim, as três categorias mais citadas foram as que tiveram a maior concordância, permanecendo as indicações: leucemia, anemia e gastrite. As indicações de uso para dor de estômago, infecções no útero, dor na gengiva e todos os tipos de infecções tiveram o menor valor, pois foram citadas por apenas um entrevistado (Tabela 5). 
Tabela 5. Valor de consenso dos informantes para os tipos de usos (VCTU) de K. coriacea

\begin{tabular}{cc}
\hline Indicação de uso medicinal & VCTU \\
\hline Leucemia & 0,0100 \\
Anemia & 0,0088 \\
Gastrite & 0,0075 \\
Vermífugo & 0,0063 \\
Dor de dente & 0,0038 \\
Cicatrização & 0,0038 \\
Dor nos rins & 0,0038 \\
Reumatismo & 0,0038 \\
Cárie & 0,0025 \\
Artrite & 0,0025 \\
Artrose & 0,0025 \\
Infecções intestinais & 0,0025 \\
Dor de estômago & 0,0013 \\
Dor na gengiva & 0,0013 \\
Todos os tipos de infecções & 0,0013 \\
Infecções de útero & 0,0013 \\
\hline
\end{tabular}

O Valor de Consenso para a Forma de Uso (VCFU) expressa a concordância entre os informantes referente às formas de uso citadas para K. coriacea. Neste sentido, foram citadas pelos informantes 11 formas de uso, sendo que a infusão $(0,20)$ e o chá $(0,16)$ as formas mais utilizadas, como pode ser observado na Tabela 6.

Tabela 6. Valor de consenso dos informantes para as formas de usos (VCFU) de K. coriacea

\begin{tabular}{cc}
\hline Forma de uso & VCFU \\
\hline Infusão & 0,20 \\
Chá & 0,16 \\
Extrair com leite; utilizar pequenas porções & 0,12 \\
diariamente & 0,12 \\
Mastigação & 0,12 \\
Amassar e deixar de molho; posteriormente tomar & 0,08 \\
Fazer um melado e utilizar como emplasto & 0,04 \\
\hline Amassar e colocar de molho na água por 24 horas &
\end{tabular}




\begin{tabular}{cc}
\hline Forma de uso & VCFU \\
\hline Chá das partes em conjunto & 0,04 \\
Fazer o emplasto & 0,04 \\
Amassar e fazer a infusão com água & 0,04 \\
Moer e fazer um melado & 0,04 \\
\hline
\end{tabular}

No que tange ao Valor de Consenso para a Parte da Planta (VCPP), os informantes indicaram a entrecasca, folhas e galhos finos, sendo a entrecasca a mais citada, como pode ser observado na Tabela 7.

Tabela 7. Valor de Consenso para a Parte da Planta (VCPP) de K. coriacea

\begin{tabular}{cc}
\hline Parte da planta & VCPP \\
\hline Entrecasca & 0,72 \\
Folhas & 0,21 \\
Galhos finos & 0,07 \\
\hline
\end{tabular}

Em função da grande indicação dos entrevistados da comunidade de Goiandira e poucos estudos encontrados na literatura sobre o assunto, a parte da planta escolhida para a referente pesquisa foi a entrecasca. Desse modo, é relevante relatar as pesquisas já realizadas com o espécime em questão, evidenciando sua importância como planta medicinal.

$\mathrm{O}$ extrato aquoso de $K$. coriacea é utilizado na medicina popular para o tratamento de várias doenças tropicais, incluindo esquistossomose, leishmaniose, malária e infecções fúngica e bacteriana (ALVES et al., 2000). Além disso, estudos científicos relatam que a planta em questão apresenta várias atividades biológicas, tais como antifúngica, antibacteriana e antimalárica (MELO E SILVA; PAULA; ESPINDOLA, 2009; CORTEZ et al., 2002; ALBERNAZ et al., 2010).

Cientificamente, o estudo realizado por Mesquita (2011) revela que a mistura do monômero de $\alpha$-tocotrienol e $\alpha$-tocotrienolperoxi-dímerooriundos do extrato hexano da casca da raiz de K. coriacea possui atividade significativa frente a células do tipo MDA-MB-435 (melanoma), HCT-8 (cólon), HL-60 (leucemia) e SF-295 (glioblastoma). A mistura em questão suprimiu o crescimento da leucemia e reduziu a sobrevivência das células, desencadeando apoptose e necrose. (MESQUITA et al., 2011) 
O resultado do Índice de Valor de Diversidade de Uso (VDU) revela que os entrevistados utilizam a entrecasca de $K$. coriacea principalmente para o tratamento dos males causados pela leucemia. Este dado correlaciona-se com pesquisas realizadas, as quais demonstram a potencialidade da planta para fins medicinais, evidenciando a corroboração entre o saber popular e a pesquisa científica.

Martins (2012) analisou o extrato etanólico da entrecasca de K. coriacea, a qual apresenta potenciais antioxidante, devido ao alto teor de compostos fenólicos e antimicrobiano, prevenindo cárie, lesões e infecções causadas por micro-organismos bucais. Os dados supramencionados podem justificar as indicações populares, em que é feito o uso da espécie por meio da mastigação da entrecasca para infecções associadas a bactérias bucais causadoras da cárie e da gengivite.

Após o tratamento das informações adquiridas nas entrevistas, bem como a busca na literatura pelos estudos referentes à K. coriacea, observou-se o seu potencial químico-biológico. Aliado a estes fatores, analisou-se o extrato etanólico da entrecasca pelas técnicas de PP e CCD, as quais indicaram a possível presença das seguintes classes de PN's: taninos e saponinas.

Os taninos são compostos fenólicos com atividade biológica importante frente a determinados micro-organismos, como agentes carcinogênicos e causadores de toxicidade hepática (SIMÕES et al., 2001). Além disso, podem agir como anti-inflamatório, cicatrizante (CHUNG; WEI; JOHNSON, 1998) e como inibidores da transcriptase reversa em HIV (KILKUSKIE et al., 1992). Ademais, a ingestão de chá verde e de dietas ricas em frutas que contêm taninos tem sido associada à atividade anticarcinogênica (CHUNG; WEI; JOHNSON, 1998). Desse modo, os taninos presentes na entrecasca da $K$. coriacea podem ser os responsáveis pela ação biológica que os moradores de Goiandira atribuem à K. coriacea.

As saponinas ou saponosídeos também foram detectadas no extrato etanólico da entrecasca de K. coriacea. Segundo Paulino et al. (2014) tais compostos são glucosídeos do metabolismo secundário vegetal, não nitrogenados e que se dissolvem em água originando soluções espumantes devido à sua ação tensoativa. Constituem um grupo heterogêneo e são classificados em glucosídeos saponosídicos do tipo esteroidale do tipo triterpênico. Atuam na defesa contra insetos e patógenos e também na manutenção do crescimento do vegetal. No ser humano possuem atividades hemolítica, anti-helmíntica, espermicida e antifúngica. Desse modo, pode-se notar a similaridade com algumas indicações da comunidade de Goiandira no uso da entrecasca do espécime estudada, como um tratamento para as enfermidades, utilizando K. coriacea em diversas maneiras de preparo como vermífugo e nos males causados por infecções intestinais. Neste sentido, com base nas informações apresentadas, nota-se que a espécie $K$. coriacea é promissora para o desenvolvimento de novos estudos de prospecção químico-biológica, os quais permitirão isolar e identificar os PNs possivelmente envolvidos nas propriedades medicinais desta planta. 


\section{CONCLUSÃO}

O uso popular de plantas com propriedades terapêuticas é considerado tradicional, disseminado por vários séculos e vem sendo passado de geração em geração, em especial em comunidades rurais e localidades com menor renda econômica. Apesar de não ser indicado o consumo de plantas sem o estudo científico, é por meio de levantamentos etnobotânicos que muitas substâncias ativas foram descobertas e se transformaram em fármacos disponíveis comercialmente. Face a isso, ressalta-se a importância do estudo em questão, o qual além de resgatar os saberes e subsidiar novas pesquisas de prospecção, possibilitará que a universidade retorne à comunidade estudada com os resultados obtidos, disseminando o conhecimento e demonstrando a importância da relação entre o saber popular e a pesquisa científica.

\section{REFERÊNCIAS}

ALBERNAZ, L. C. et al. Investigation of plant extracts in traditional medicine of the Brazilian Cerrado against protozoans and yeasts. Journal of Ethnopharmacology, v.131, n. 1, p.116-21, ago, 2010.

ALMEIDA, G. Cortiças. Revista Florestal. Rio de Janeiro, v. 8, p. 10-24, 1946.

ALVES, T. M. de A. et al. Biological screening of Brazilian medicinal plants. Memórias do Instituto Oswaldo Cruz, Rio de Janeiro, v. 95, n.3, p. 367-373, mai./jun, 2000.

ARAÚJO, V. J. História da Terra Branca e outras coisas mais. Goiânia: Kelps, 2000.

AURICCHIO, M. T.; BACCHI, E. M. Folhas de Eugenia uniflora L. (pitanga): propriedades farmacobotânicas, químicas e farmacológicas. Revisão. Rev. Inst. Adolfo Lutz, v. 62, n. 1, p. 55- 61, 2003.

BECKER, H. S. Métodos de pesquisa em ciências sociais. São Paulo: Hucitec, 1993. CHUNG, K.; WEI, C.; JOHNSON, M. G. Are tannins a double-edged sword in biology and health? Trends in Food Science \& Technology, Cambridge, v. 9, n. 4, p. 168-175, 1998.

CORTEZ, D. A. G. et al. Antibacterial activity of a biphenyl and xanthones form Kielmeyeria coriacea. Pharmaceutical Biology, v. 40, n.7 485-9, 2002.

FEITOSA, I. S. Etnobotânica e extrativismo de Stryphnodendron coriaceum Benth. na Floresta Nacional do Araripe, nordeste do Brasil. Dissertação (Mestrado em Botânica), Universidade Federal Rural de Pernambuco, Recife, 2012. 83 p.

FERREIRA, F. et al. Levantamento de plantas medicinais e do conhecimento etnobotânico no município de Baependi, Minas Gerais, Brasil MG. BIOTA, Belo Horizonte, v.5, n.6, fev./mar. 2013.

GUARIM NETO, G.; MORAIS, R. G. Recursos medicinais de espécies do Cerrado de Mato Grosso: um estudo bibliográfico. Acta bot. bras. 17(4): 561-584, 2003 
IBGE. Instituto Brasileiro de Geografia e Estatística. Banco de dados de Goiandira. Disponível em: <http://www.ibge.gov.br/cidadesat/topwindow.htm?1>. Acesso em: 5 mai. 2012.

JORGE, R. Calophyllaceae. In: MARTINELLI, G. MESSINA, T.; SANTOS FILHO, L. (Org.) O livro vermelho da flora do Brasil: plantas raras do Cerrado. Rio de Janeiro: Andrea Jakobson: Instituto de Pesquisas Jardim Botânico do Rio de Janeiro: CNCFlora, 2014. p. 80-81.

KILKUSKIE, R. E. et al. HIV and reverse transcriptase inhibition by tannins. Bioorganic \& Medicmal Chemistry Lemrs.v.2, n.12, p. 1529.1534, 1992.

LIMA, I. L. P. et al. C. Diversidade e uso de plantas do Cerrado em comunidade de raizeiros no norte do estado de Minas Gerais, Brasil. Acta BotanicaBrasilica, v. 26, n. 3, p. 675-684, 2012.

LORENZI, H. Árvores brasileiras: manual de identificação e cultivo de plantas arbóreas nativas do Brasil. São Paulo: Nova Odessa, 1992.

MACIEL, M. M. A. et al. Plantas medicinais: a necessidade de estudos multidisciplinares. Química Nova, São Paulo, v. 25, n. 3, p. 429-438, 2002.

MARTINELLI, G. et al. Avaliações de risco de extinção das plantas raras do Cerrado: resultados, desafios e perspectivas.p. 25-41. In: MARTINELLI, G. MESSINA, T.; SANTOS FILHO, L. (Org.) O livro vermelho da flora do Brasil: plantas raras do Cerrado. Rio de Janeiro: Andrea Jakobsson: Instituto de Pesquisas Jardim Botânico do Rio de Janeiro: CNCFlora, 2014.

MARTINS, C. M. Estudo Químico Atividade Antioxidante, atividade antimicrobiana e análise do óleo essencial da espécie Kielmeyera coriácea Mart. \& Zucc (pau-santo) do Cerrado. Dissertação (Mestrado) - Programa de Pós-Graduação em Química, Universidade Federal de Uberlândia, Uberlândia, 2012. 117 p.

MATOS, F. J. A. A introdução à fitoquímica experimental. 2. ed. Fortaleza: Edições UFC, 1997.

MELLO, J. C. P. et al. Farmacognosia: da planta ao medicamento. 3. ed. Porto Alegre: UFSC, 2001.

MELO E SILVA, F.; PAULA, J. E.; ESPINDOLA, L. S. Evaluation of the antifungal potential of Brazilian Cerrado medicinal plants. Mycoses, v.52, p. 511-517, 2009.

MESQUITA, M. L. et al. Cytotoxicity of d-tocotrienols from Kielmeyeracoriacea against cancer cell lines. Bioorganic \& Medicinal Chemistry, vol. 19, n. 1, p. 623-630, 2011. MITTERMEIER, R. A.; MYERS, N.; MITTERMEIER, C. G.; ROBLES G. P. Hotspots: Earth's biologically richest and most endangered terrestrial ecoregions. Sierra Madre: Cemex, 1999.

PAULINO, B. L. et al. Utilização de saponinas triterpênicas no combate às larvas do Aedes aegypti. In: III Simpósio de Ciências Farmacêuticas. Anais... Centro Universitário São Camilo, 2014.

PEREIRA; R. J.; CARDOSO, M. G. Metabólitos secundários vegetais e benefícios antioxidantes. J. Biotec. Biodivers, v. 3, n. 4, p. 146-152, 2012. 
RODRIGUES, E.; CARLINI, E. A. Ritual use of plants with possible action on the central nervous system by the Kraho Indians, Brazil. Phytotherapy Research, v. 19, p. 129-135, 2005.

CAMEJO RODRIGUES, J. S. Estudo etnobotânico das plantas aromáticas e medicinais. Curso teórico - prático. Ameal. v. 8, n. 57, p. 168- 174, 2007.

RODRIGUES, V. E. G.; CARVALHO, D. A. Levantamento etnobotânico de plantas medicinais no domíniodo cerrado na região do Alto Rio Grande - Minas Gerais. Ciênc. Agrotec. Lavras, v. 25, n. 1, p. 102-123, jan./fev. 2001.

SÁ, A. P. C. S. Potencial antioxidante e aspectosquímicos e físicos das frações comestíveis (polpa e cascas) e sementes de Jamelão (Syzygiumcumini, L. Skeels). Dissertação (Mestrado em Ciência e Tecnologia de Alimentos) - Universidade Federal Rural do Rio de Janeiro, 2008.

SCARANO, F. R. et al. O bioma Cerrado: conservação e ameaças. In: MARTINELLI, G.; MESSINA, T.; SANTOS FILHO, L. (Org.) O livro Vermelho da Flora do Brasil: Plantas raras do Cerrado. Rio de Janeiro: Andrea Jakobson: Instituto de Pesquisas Jardim Botânico do Rio de Janeiro: CNC Flora, 2014.p. 21-24.

SIMÕES, C. M. O. et al. Farmacognosia: da planta ao medicamento. 3. ed. Porto Alegre: Ed. da UFSC, 2001.

SOUZA, C. D.; FELFILE, J. M. Uso de plantas medicinais na região de Alto Paraíso de Goiás, GO, Brasil. Acta bot. bras. v. 20, n. 1, p. 135-142, 2006.

THIOLLENT, M. Metodologia da pesquisa- ação. São Paulo: Cortez. 1994. 
